\title{
Pantoprazole before Endoscopy in Patients with Gastroduodenal Ulcer Bleeding: Does the duration of Infusion and Ulcer Location Influence the Effects?
}

\author{
Istvan Rácz, ${ }^{1,2}$ Milan Szalai, ${ }^{1}$ Nora Dancs, ${ }^{1}$ Tibor Kárász, ${ }^{1}$ Andrea Szabó, ${ }^{1}$ \\ Mihaly Csöndes, ${ }^{1}$ and Zoltan Horváth ${ }^{2}$ \\ ${ }^{1}$ Department of Gastroenterology, Petz Aladár Teaching Hospital, Gyor 9024, Hungary \\ ${ }^{2}$ Department of Mathematics and Computer Sciences, Széchenyi István University, Györ 9026, Hungary
}

Correspondence should be addressed to Istvan Rácz, raczi@petz.gyor.hu

Received 15 June 2012; Accepted 14 September 2012

Academic Editor: Sergio Morini

Copyright (c) 2012 Istvan Rácz et al. This is an open access article distributed under the Creative Commons Attribution License, which permits unrestricted use, distribution, and reproduction in any medium, provided the original work is properly cited.

The aim of this study was to investigate the effect of preemptive pantoprazole infusion on early endoscopic findings in patients with acute ulcer bleeding. Records of 333 patients admitted with acute ulcer bleeding were analyzed. Ulcer bleeders were given either $80 \mathrm{mg}$ bolus of pantoprazole followed by continuous infusion of $8 \mathrm{mg}$ per hour or saline infusion until endoscopy. In 93 patients saline infusion whereas in 240 patients bolus plus infusion of pantoprazole was administrated with mean $( \pm \mathrm{SD})$ durations of $5.45 \pm$ 12.9 hours and $6.9 \pm 13.2$ hours, respectively $(P=0.29)$. Actively bleeding ulcers were detected in $46 / 240(19.2 \%)$ of cases in the pantoprazole group as compared with $23 / 93(24.7 \%)$ in the saline infusion group $(P=0.26)$. Different durations of pantoprazole infusion ( $0-4$ hours, $>4$ hours, and $>6$ hours) had no significant effect on endoscopic and clinical outcome parameters in duodenal ulcer bleeders. Gastric ulcer bleeders on pantoprazole infusion longer than 4 and 6 hours before endoscopy had actively bleeding ulcers in $4.3 \%$ and $5 \%$ compared to the $19.5 \%$ active bleeding rate in the saline group $(P=0.02$ and $P=0.04)$. Preemptive infusion of high-dose pantoprazole longer than 4 hours before endoscopy decreased the ratio of active bleeding only in gastric but not in duodenal ulcer patients.

\section{Introduction}

In patients with bleeding peptic ulcers infusion of high-dose proton pump inhibitor (PPI) after endoscopic hemostasis reduces recurrent bleeding and improves clinical outcomes [1-6]. High-dose proton pump inhibitors administered intravenously increase and maintain gastric $\mathrm{pH}$ above 6, which is thought to be beneficial for platelet aggregation and clot formation over bleeding vessels [7-9]. Recent studies have shown that not only postendoscopic but also preendoscopic high-dose proton pump inhibitor therapy significantly reduces the proportion of patients with high-risk stigmata of recent hemorrhage (active bleeding, nonbleeding visible vessel, and adherent clot) at early endoscopy and decreases the need for endoscopic intervention $[10,11]$. However, almost no data exist about the minimally required duration of PPI infusion before endoscopy, whose results downstage the endoscopic lesions and decrease the need for endoscopic intervention [12]. We hypothesized that patients undergoing endoscopy almost immediately after PPI administration may likely utilize only few benefits whereas longer duration of preendoscopic PPI infusion more likely generates clinical benefits.

The aim of our retrospective case control study was to investigate the effects of preemptive infusion of pantoprazole before endoscopy on early endoscopic findings and clinical outcomes in patients with gastroduodenal ulcer bleeding. We also aimed to estimate the threshold duration of pantoprazole infusion before endoscopy ensuring downstage of endoscopic lesions. Furthermore, we separately analyzed the effect of preendoscopic pantoprazole infusion in patients with gastric and duodenal ulcer bleeding.

\section{Patients and Methods}

2.1. Study Design. This was a single-center, retrospective, comparative cohort study. The study protocol was approved 
by the Regional Ethics Committee of the Petz Aladár Teaching Hospital. There was no pharmaceutical industry support for this study.

2.2. Patients. Data collection was carried out by use of the files of those patients who presented with the signs of acute upper gastrointestinal bleeding (i.e., melena or hematemesis with or without hypotension) during the evening and night hours (6 PM-8 AM) at the Gastroenterology Emergency Department of the Petz Aladár Teaching Hospital in Győr. All patients were evaluated by admitting as residents according to the actual patient managing protocols. Patients with hypotensive shock (systolic RR $\leq 90 \mathrm{Hgmm}$ or pulse $\geq 110$ beats per minute) were initially resuscitated to stabilize their condition. Patients with continuous shock symptoms despite resuscitation activity underwent immediate urgent endoscopy by the on-call endoscopy team and these patients were excluded from the study analysis.

According to the hospital practice protocol for patients who had bleeding ulcers associated with intake of nonsteroidal anti-inflammatory drugs (NSAIDs) or aspirin, the drugs were discontinued. Fresh-frozen plasma was given to those bleeders who were on coumarin therapy. Anticoagulation-dependent cardiac or postthrombosis patients underwent low-molecular-weight heparin therapy until the bleeding was stabilized.

Medical records of 1369 consecutive patients admitted with upper gastrointestinal bleeding between April 2007 and July 2011 were retrospectively analyzed. In this time period all diagnostic and therapeutic procedures were performed by the same hospital managing protocol except the use of intravenous proton pump inhibitor (PPI) while awaiting an early endoscopy. The preemptive PPI use was included in the managing protocol of the gastrointestinal bleeders arriving during the evening and night time in January 2009. Since that time all acute bleeders with the suspicion of upper GI bleeding were given an $80 \mathrm{mg}$ intravenous bolus injection of pantoprazole followed by continuous infusion of $8 \mathrm{mg}$ per hour until endoscopic examination the next morning. Before that, during 2007 and 2008 saline infusion was administrated to all patients during the preendoscopy hospital period and PPI infusion was initiated only after endoscopy in patients with ulcer bleeding. This difference in the preendoscopy infusion policy offers the possibility to evaluate whether high-dose intravenous pantoprazole before endoscopy would have a therapeutic effect on bleeding ulcers, reduce the need for endoscopic therapy, and result in improved clinical outcomes.

Use of pantoprazole or saline was started at admission and was continuously given also during the endoscopy. In patients with signs of ongoing bleeding (i.e., repeated hematemesis or fresh blood in the nasogastric tube) an urgent endoscopy was performed by the endoscopic on-call team. In all other cases with stabilized condition the early endoscopy was performed next morning by expert endoscopists.

At endoscopy the Forrest classification was used to define the bleeding ulcers. Those ulcers with spurting bleeding, oozing bleeding, or nonbleeding visible vessels (Forrest Ia, $\mathrm{Ib}$, and IIa) were injected with $1: 10.000$ diluted epinephrine followed by coaptive thermocoagulation or hemoclip application.

Hemostasis was considered successful if bleeding had stopped and if the visible bleeding vessels disappeared or were cavitated. Clots covering ulcers were firmly irrigated by water after injection with diluted epinephrine around the ulcer and underlying vessels, if the present were treated. To examine whether Helicobacter pylori (H. pylori) infection was present antral biopsies were taken for rapid urea test and histology.

Patients with no need for endoscopic therapy were transferred to general medical wards. Those patients who underwent endoscopic hemostasis were admitted to the highdependency gastroenterology ward for monitoring. For those patients who required endoscopic ulcer hemostasis $8 \mathrm{mg}$ per hour pantoprazole was infused for 72 hours after endoscopy.

Rebleeding was considered if any of the following events occurred: repeated vomiting of fresh blood, hypotensive shock (defined as systolic blood pressure $\leq 90 \mathrm{Hgmm}$ or a pulse $\geq 110$ beats per minute) with melena after stabilization, or decrease in the hemoglobin level of more than $2 \mathrm{~g} / \mathrm{dL}$ within 24 hours after transfusion, resulting in a hemoglobin level of $10 \mathrm{~g} / \mathrm{dL}$ or less. Patients who were judged to be rebleeders underwent repeated endoscopy either by the oncall duty team or by the regular daily expert endoscopists. Rebleeding was confirmed in cases with Forrest Ia, Ib ulcers, or if there was fresh blood in the stomach either with a Forrest IIa or IIb ulcer. Endoscopic hemostatic therapy was repeated in cases with rebleeding ulcers. Surgery was indicated if the bleeding could not be controlled endoscopically or in cases with second rebleeding.

After the 72-hour infusion of pantoprazole, patients were given $40 \mathrm{mg}$ per day pantoprazole orally for 8 weeks. The same oral therapy was administrated in cases with Forrest IIc and III ulcers at first endoscopy. In patients who were $H$. pylori positive according to either the rapid urease test or by histology a one-week eradication therapy $(2 \times$ $40 \mathrm{mg}$ pantoprazole twice daily and $500 \mathrm{mg}$ clarithromycin and $1 \mathrm{~g}$ amoxicillin twice daily) was started 3 days after the onset of bleeding. That was followed by $40 \mathrm{mg} /$ daypantoprazole treatment for the remaining six weeks. Patients were regularly followed up to 30 days after hospital admission by the contact of the family doctors or by their controls in the hospital outpatient offices. Clinic followup, hospital readmissions, or death were checked and verified through the computerized hospital record system.

In our retrospective analysis the primary outcome was the active bleeding at the first endoscopic examination. Secondary outcomes included the need for endoscopic hemostasis at the first endoscopy, need for urgent endoscopy, rates of rebleeding, need for emergency surgery, and death from any reason within 30 days of hospital admission. Both primary and secondary outcomes were analyzed also in subgroups of patients with different durations of intravenous pantoprazole administration before the first endoscopy. Furthermore, all these analyses were performed separately both in duodenal and gastric ulcer patients. 
2.3. Statistical Analysis. Student's $t$ test was used to analyze age, hemoglobin, and shock symptoms. All other parameters were primarily analyzed with Chi-square test and the latter was replaced with Fischer's exact test when the numbers of data were insufficient. All tests of significance were two tailed, and a $P$ value of 0.05 was considered to indicate statistical significance.

\section{Results}

Between April 2007 and July 2011 a total of 1369 patients were admitted to our emergency unit with the signs of acute upper gastrointestinal bleeding. A total of 1036 patients were excluded from our retrospective analysis: a total of 612 patients were admitted in nonduty hours; in 392 patients the endoscopy detected nonulcer sources of bleeding, and in 32 cases essential data were missing in their records. Finally, clinical and endoscopic data were analyzed for those 333 gastroduodenal ulcer bleeding patients who were admitted in duty hours and the endoscopy examinations were done either in the next morning or urgently. Before endoscopy saline infusion was administrated in 93 patients whereas in 240 patients bolus plus infusion pantoprazole was started (Figure 1).

Demographic and clinical characteristics were similar in the two groups (Table 1). The source of bleeding was duodenal ulcer in 47 of 93 patients $(50.5 \%)$ in the saline infusion group and 128 of $240(53.3 \%)$ in the pantoprazole group. The mean $( \pm$ SD) duration of infusion before endoscopy was $5.45 \pm 12.9$ hours in the saline group and $6.9 \pm 13.2$ hours in the pantoprazole group $(P=0.29)$.

Among the 240 patients in the pantoprazole group during the first endoscopic examinations actively bleeding ulcers were detected in $46(19.2 \%)$ cases, as compared with 23 of the 93 patients $(24.7 \%)$ in the saline infusion group $(P=0.26)$. The ratio of ulcers with nonbleeding visible vessels, clots, pigmented spots, and clean base also did not differ significantly in the two groups (Table 2). At the first endoscopy 147 of 240 patients $(61.3 \%)$ in the pantoprazole group and 53 of 93 patients $(56.9 \%)$ in the saline group required endoscopic treatment $(P=0.82)$. Urgent endoscopy was performed in $19(7.9 \%)$ pantoprazole group patients and in $8(8.6 \%)$ in the saline group patients $(P=$ $0.89)$.

Emergency surgery was performed in 21 patients $(8.8 \%)$ in the pantoprazole and in 10 patients $(10.7 \%)$ in the saline group $(P=0.57)$. Recurrent bleeding occurred in 40 patients $(16.7 \%)$ in the pantoprazole group and 13 patients (13.9\%) in the saline group $(P=0.55)$. Within 30 days after hospital admission 15 patients $(6.3 \%)$ in the pantoprazole group and 4 patients $(4.3 \%)$ in the saline group died $(P=0.49)$.

When analyzing all ulcer patients $(n=333)$ the duration of pantoprazole infusion had no significant effect on outcome parameters compared to the saline infusion patients except the significantly increased ratio of ulcers with clot in patients who were on pantoprazole infusion up to 4 hours (25.3\% versus $12.9 \% ; P=0.02$ ).

In the subgroup of the 175 duodenal ulcer patients the preemptive bolus + pantoprazole infusion therapy compared to saline infusion had no significant effect neither on endoscopic appearance of ulcers nor on clinical outcome measures. In duodenal ulcer bleeders the duration of pantoprazole infusion $(0-4 \mathrm{hrs},>4 \mathrm{hrs}$, and $>6 \mathrm{hrs})$ also had no significant effect on the endoscopic appearance of ulcers at the first endoscopy and on clinical outcomes (Table 3).

In contrary, when analyzing the subgroup of the 158 gastric ulcer bleeders in those patients who were on pantoprazole infusion longer than 4 and 6 hours the ratios of actively bleeding ulcers were only $4.3 \%$ and $5 \%$ compared to the $19.5 \%$ actively bleeding ulcer rate in the saline infusion group $(P=0.02$ and $P=0.04$ ) (Table 4). In addition, a significantly higher proportions of gastric ulcers were covered by clot at the first endoscopy in those patients who received pantoprazole infusion up to 4 hours compared to those gastric ulcer bleeders on saline infusion $(30.8 \%$ versus $10.9 \%, P=0.01$ ). Similarly to duodenal ulcer bleeders in patients with gastric ulcer bleeding any analyzed duration of the preendoscopic pantoprazole infusion had no significant modification on clinical outcomes as observed with saline infusion only.

\section{Discussion}

Our retrospective analyses only partly reaffirm the efficacy of parenteral PPI treatment initiated before the endoscopy for gastroduodenal ulcer bleeding. In our study early administration of high-dose pantoprazole did not reduce significantly the ratio of active bleeding and the need for endotherapy at the first endoscopy among the total cohort of gastroduodenal ulcer bleeders compared to the saline infusion group. Moreover, no significant differences were detected between the two patient cohorts in any clinical outcomes.

In a placebo-controlled randomized clinical trial that involved endoscopic therapy, Lau et al. found that fewer cases of actively bleeding peptic ulcers were seen among patients who received high-dose i.v. omeprazole before endoscopy than among those who had received placebo [10]. In this study early administration of high-dose omeprazole also reduced the need for endoscopic therapy but had no beneficial effect on clinical outcomes. A recent Cochrane meta-analysis of six randomized trials of preendoscopic PPI therapy also found the same results [11].

The notion that acid suppression facilitates clot formation and confers clot stability over arteries in bleeding peptic ulcers is the theoretical background of i.v. PPI therapy either in postendoscopic and preendoscopic settings [7-9, 13].

Regarding preemptive i.v. PPI treatment one key variable for which there exist only limited data is the time elapsed on PPI therapy until endoscopy [12]. In the Lau trial the mean duration of intravenous omeprazole administration before the endoscopy was $14.7 \pm 6.3$ hours which is more than twice as long as the mean duration of i.v. pantoprazole infusion therapy in our study ( $6.9 \pm 13.2$ hours). It can be postulated that if patients undergo endoscopy within only few hours or almost immediately after PPI administration it may likely utilize only few clinical benefits. Alternatively, if 


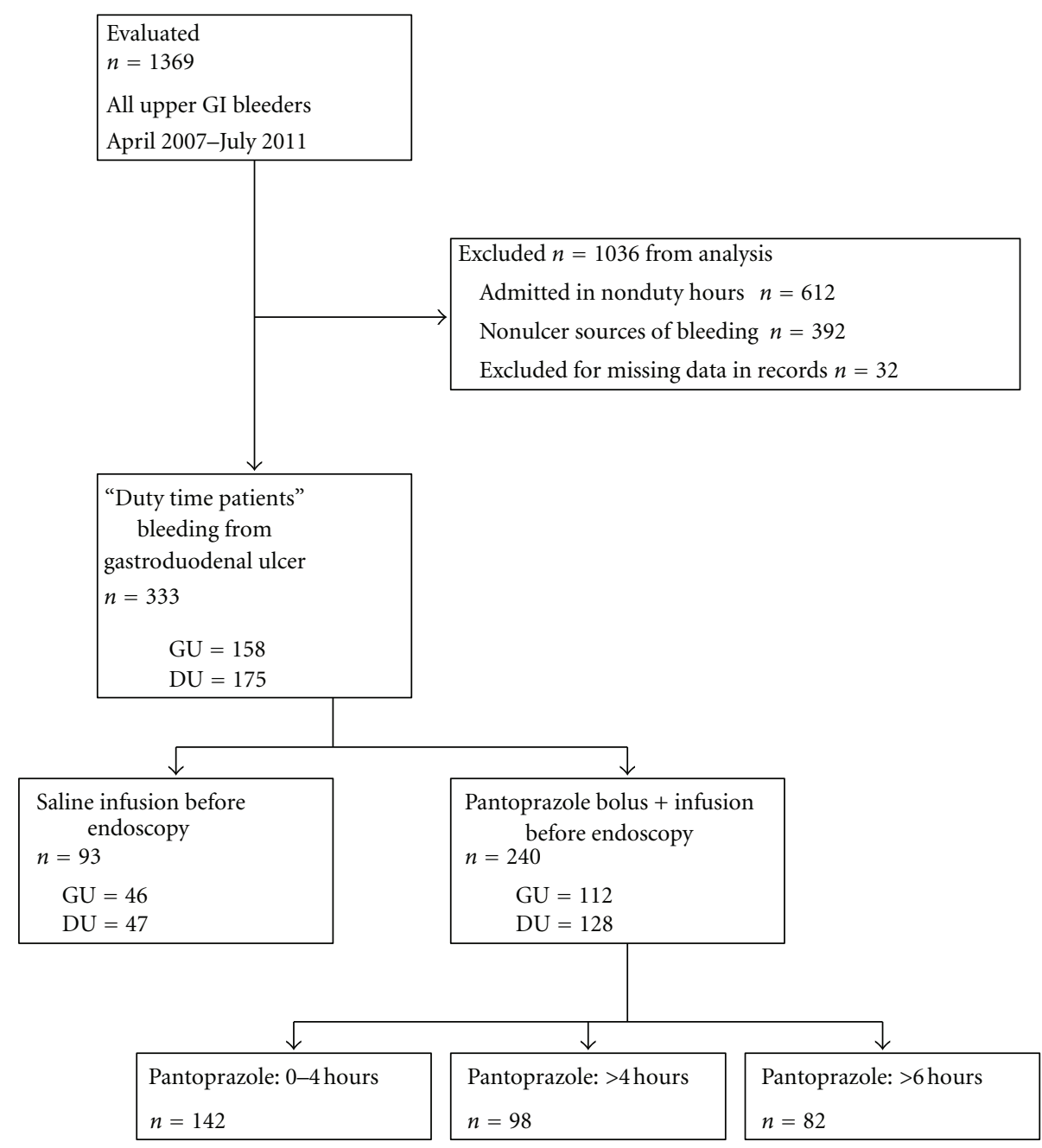

GU: gastric ulcer

DU: duodenal ulcer

FIGURE 1: Patient distribution and groups of retrospective analysis.

patients undergo endoscopy more later after the start of PPI treatment the more clinical benefits can be achieved. In our retrospective analysis we tried to find the threshold duration of pantoprazole administration being effective either in primary or in secondary outcomes. Pantoprazole infusion durations ( $0-4$ hours, $>4$ hours, and $>6$ hours) had no significant downstaging effect on endoscopic lesions except increased early clot formation ratio when compared to saline infusion. However, a tendency of less active bleeding was seen with longer pantoprazole treatment in the total cohort of gastroduodenal bleeders.

The differences between the Lau study and our results regarding the proportion of actively bleeding ulcers and the need for endoscopic therapy at first endoscopy can be explained at least partly by the markedly different durations of preemptive PPI therapy.
Longer duration of PPI treatment in the Lau study resulted in significant benefits. Analyzing and comparing the results of both studies one may speculate that the threshold duration of effective preendoscopic PPI treatment may therefore exist in between 6-14 hours.

The initial step of hemostasis is clot formation on ulcers in $\mathrm{pH}$ dependent. Data from in vitro studies have shown that gastric $\mathrm{pH}$ above 6 is the optimal for platelet aggregation [79]. Avgerinos et al. performed a clinical trial to examine the rapidity and maintain intragastric $\mathrm{pH}$ elevation in gastroduodenal ulcer bleeding patients receiving an initial $80 \mathrm{mg}$ bolus injection followed by $8 \mathrm{mg} / \mathrm{h}$ continuous infusion of pantoprazole [14]. In their study the mean percentage of time spent above $\mathrm{pH} 6.0$ during the first 12 hours of the pantoprazole infusion period was only $43.3 \%$. For the time period of $0-4$ hours the mean $\mathrm{pH}$ in the fundus was not 
TABLE 1: Characteristics of 333 gastroduodenal ulcer bleeding patients included in the retrospective analysis.

\begin{tabular}{|c|c|c|c|}
\hline Characteristic & Pantoprazole $(n=240)$ & Saline $(n=93)$ & $P$ value \\
\hline Age-year & $63.4 \pm 15.2$ & $66.0 \pm 13.4$ & 0.12 \\
\hline Male sex-number (\%) & $175(72.9 \%)$ & $59(63.4 \%)$ & 0.08 \\
\hline Hemoglobin-g/dL & $95.3 \pm 30.1$ & $96.8 \pm 30.4$ & 0.68 \\
\hline Shock symptoms-number of patient (\%) & $22(9.2 \%)$ & $3(3.2 \%)$ & 0.06 \\
\hline \multicolumn{4}{|l|}{ Coexisting illness-number of patients (\%) } \\
\hline Cirrhosis & $40(16.6 \%)$ & $16(17.2 \%)$ & 0.90 \\
\hline Cardiovascular & $146(60.8 \%)$ & $58(62.3 \%)$ & 0.79 \\
\hline Helicobacter pylori infection-number of patients (\%) & $73(30.4 \%)$ & $33(35.4 \%)$ & 0.37 \\
\hline \multicolumn{4}{|l|}{ Risk factors for bleeding — number of patients (\%) } \\
\hline NSAID and/or aspirin & $120(50.0 \%)$ & $42(45.2 \%)$ & 0.42 \\
\hline Anticoagulant & $19(7.9 \%)$ & $8(8.6 \%)$ & 0.83 \\
\hline Previous gastroduodenal ulcer & $74(30.8 \%)$ & $28(30.1 \%)$ & 0.89 \\
\hline \multicolumn{4}{|l|}{ Source of bleeding } \\
\hline Duodenal ulcer & $128(53.3 \%)$ & $47(50.5 \%)$ & 0.64 \\
\hline Gastric ulcer & $112(46.7 \%)$ & $46(49.5 \%)$ & 0.64 \\
\hline \multicolumn{4}{|l|}{ Symptom at presentation-number of patients $(\%)$} \\
\hline Melena & $177(73.7 \%)$ & $65(69.9 \%)$ & 0.47 \\
\hline Hematemesis & $111(46.2 \%)$ & $36(38.7 \%)$ & 0.21 \\
\hline Both & $60(25.0 \%)$ & $16(17.2 \%)$ & 0.12 \\
\hline Duration of infusion before endoscopy (hours) & $6.9 \pm 13.2$ & $5.45 \pm 12.9$ & 0.29 \\
\hline
\end{tabular}

TABLE 2: Outcomes with different durations of pantoprazole infusion compared to saline infusion for the total of 333 gastroduodenal ulcer bleeders.

\begin{tabular}{|c|c|c|c|c|c|c|c|c|c|}
\hline \multirow{3}{*}{ Outcome (all ulcer bleeders) } & Saline & $\begin{array}{c}\text { Pantoprazole } \\
\text { all }\end{array}$ & & $\begin{array}{c}\text { Pantoprazole } \\
0-4 \text { hrs }\end{array}$ & \multirow{3}{*}{$\begin{array}{c}P \\
\text { value }\end{array}$} & $\begin{array}{c}\text { Pantoprazole } \\
>4 \text { hrs }\end{array}$ & & $\begin{array}{c}\text { Pantoprazole } \\
>6 \text { hrs }\end{array}$ & \\
\hline & $(n=93)$ & $(n=240)$ & $\begin{array}{c}P \\
\text { value }\end{array}$ & $(n=142)$ & & $(n=98)$ & $\begin{array}{c}P \\
\text { value }\end{array}$ & $(n=82)$ & $\begin{array}{c}P \\
\text { value }\end{array}$ \\
\hline & \multicolumn{2}{|c|}{ Number of pts. (\%) } & & $\begin{array}{c}\text { Number of } \\
\text { pts. }(\%)\end{array}$ & & $\begin{array}{c}\text { Number of } \\
\text { pts. }(\%)\end{array}$ & & $\begin{array}{c}\text { Number of } \\
\text { pts. (\%) }\end{array}$ & \\
\hline \multicolumn{10}{|l|}{ Endoscopic signs of bleeding } \\
\hline Active bleeding & $23(24.7 \%)$ & $46(19.2 \%)$ & 0.26 & $32(22.5 \%)$ & 0.69 & $14(14.3 \%)$ & 0.07 & $12(14.6 \%)$ & 0.09 \\
\hline Nonbleeding visible vessel & $18(19.3 \%)$ & $49(20.4 \%)$ & 0.83 & $29(20.4 \%)$ & 0.84 & $20(20.4 \%)$ & 0.86 & $19(23.2 \%)$ & 0.54 \\
\hline Clot & $12(12.9 \%)$ & $52(21.7 \%)$ & 0.50 & $36(25.3 \%)$ & 0.02 & $16(16.3 \%)$ & 0.50 & $14(27.1 \%)$ & 0.44 \\
\hline Pigmented spot and clean base & $40(43.0 \%)$ & $93(38.8 \%)$ & 0.48 & $45(31.6 \%)$ & 0.08 & $48(48.9 \%)$ & 0.41 & $37(45.1 \%)$ & 0.78 \\
\hline Urgent endoscopy & $8(8.6 \%)$ & $19(7.9 \%)$ & 0.89 & $12(8.4 \%)$ & 0.91 & $7(7.1 \%)$ & 0.84 & $5(6.1 \%)$ & 0.64 \\
\hline Recurrent bleeding & $13(13.9 \%)$ & $40(16.7 \%)$ & 0.55 & $21(14.8 \%)$ & 0.86 & $19(19.4 \%)$ & 0.32 & $17(20.1 \%)$ & 0.24 \\
\hline Emergency surgery & $10(10.7 \%)$ & $21(8.8 \%)$ & 0.57 & $13(9.2 \%)$ & 0.68 & $8(8.2 \%)$ & 0.54 & $7(8.5 \%)$ & 0.62 \\
\hline Mortality & $4(4.3 \%)$ & $15(6.3 \%)$ & 0.49 & $8(5.6 \%)$ & 0.65 & $7(7.1 \%)$ & 0.39 & $5(6.1 \%)$ & 0.59 \\
\hline
\end{tabular}

$P$ values were calculated for comparison between saline infusion group and pantoprazole infusion group patients with different durations of pantoprazole administration.

higher than in the placebo group. These results suggest that the hemostatic effect of preemptive parenteral PPI therapy might be not only $\mathrm{pH}$ dependent but also time dependent.

According to our knowledge our study is the first which separately analyzed the effects of preendoscopic pantoprazole infusion in the subgroups of duodenal and gastric ulcer bleeders. Similarly to the total cohort of all gastroduodenal bleeders independently of pantoprazole infusion duration no significant modification of the outcome measures was seen in the 128 patients bleeding from duodenal ulcers compared to the saline group. In contrary, longer than 4 hours duration of pantoprazole infusions significantly reduced the ratio of active bleeding at first endoscopy among those 112 patients who bled from gastric ulcers. These latter results may reflect that clot formation activity related to pantoprazole-induced acid suppression has different rapidity and potential in the stomach compared to the duodenum.

Several factors limit the value of our findings. First, it was a retrospective study with typical inherent limitations of the retrospective analysis. Second, long-term aspirin and NSAID as well as anticoagulant users were not excluded from the analysis; therefore patients enrolled in our study may have 
TABLE 3: Outcomes for the 175 duodenal ulcer bleeders with different durations of pantoprazole infusion compared to saline infusion.

\begin{tabular}{|c|c|c|c|c|c|c|c|c|c|}
\hline \multirow{3}{*}{$\begin{array}{l}\text { Outcome (duodenal ulcer } \\
\text { bleeders) }\end{array}$} & Saline & $\begin{array}{l}\text { Pantoprazole } \\
\text { all }\end{array}$ & & $\begin{array}{l}\text { Pantoprazole } \\
0-4 \text { hrs }\end{array}$ & \multirow{3}{*}{$\begin{array}{c}P \\
\text { value }\end{array}$} & $\begin{array}{l}\text { Pantoprazole } \\
>4 \text { hrs }\end{array}$ & & $\begin{array}{l}\text { Pantoprazole } \\
>6 \mathrm{hrs}\end{array}$ & \multirow{3}{*}{$\begin{array}{c}P \\
\text { value }\end{array}$} \\
\hline & $(n=47)$ & $(n=128)$ & $\begin{array}{c}P \\
\text { value }\end{array}$ & $(n=77)$ & & $(n=51)$ & $\begin{array}{c}P \\
\text { value }\end{array}$ & $(n=42)$ & \\
\hline & \multicolumn{2}{|c|}{ Number of pts. (\%) } & & $\begin{array}{l}\text { Number of } \\
\text { pts. }(\%)\end{array}$ & & $\begin{array}{l}\text { Number of } \\
\text { pts. }(\%)\end{array}$ & & $\begin{array}{l}\text { Number of } \\
\text { pts. }(\%)\end{array}$ & \\
\hline \multicolumn{10}{|l|}{$\begin{array}{l}\text { Endoscopic signs of bleeding } \\
\text { from duodenal ulcers }\end{array}$} \\
\hline Active bleeding & $14(29.8 \%)$ & $31(24.2 \%)$ & 0.46 & $19(24.6 \%)$ & 0.53 & $12(23.5 \%)$ & 0.48 & $10(23.8 \%)$ & 0.53 \\
\hline Nonbleeding visible vessel & $7(14.8 \%)$ & $27(21.1 \%)$ & 0.36 & $17(22.0 \%)$ & 0.33 & $10(19.6 \%)$ & 0.54 & $9(21.4 \%)$ & 0.42 \\
\hline Clot & $7(14.8 \%)$ & $24(18.7 \%)$ & 0.55 & $16(20.8 \%)$ & 0.41 & $8(15.7 \%)$ & 0.91 & $8(19.0 \%)$ & 0.60 \\
\hline Pigmented spot and clean base & $19(40.4 \%)$ & $46(35.9 \%)$ & 0.59 & $25(32.5 \%)$ & 0.36 & $21(0.41 \%)$ & 0.94 & $15(35.7 \%)$ & 0.65 \\
\hline Urgent endoscopy & $5(10.6 \%)$ & $11(8.5 \%)$ & 0.64 & $6(7.8 \%)$ & 0.52 & $5(9.8 \%)$ & 0.82 & $3(7.1 \%)$ & 0.54 \\
\hline Recurrent bleeding & $9(19.1 \%)$ & $22(17.2 \%)$ & 0.76 & $11(14.2 \%)$ & 0.47 & $11(21.5 \%)$ & 0.77 & $10(23.8 \%)$ & 0.59 \\
\hline Emergency surgery & $8(17.0 \%)$ & $15(12.3 \%)$ & 0.36 & $8(10.4 \%)$ & 0.28 & $7(13.7 \%)$ & 0.81 & $6(14.3 \%)$ & 0.72 \\
\hline Mortality & $3(6.3 \%)$ & $7(5.7 \%)$ & 0.76 & $5(6.4 \%)$ & 0.98 & $2(3.9 \%)$ & 0.58 & $1(2.3 \%)$ & 0.36 \\
\hline
\end{tabular}

$P$ values were calculated for comparison between saline infusion group and pantoprazole infusion group patients with different durations of pantoprazole administration.

TABle 4: Outcomes for the 158 gastric ulcer bleeders with different durations of pantoparazole infusion compared to saline infusion.

\begin{tabular}{|c|c|c|c|c|c|c|c|c|c|}
\hline \multirow{3}{*}{ Outcome (gastric ulcer bleeders) } & Saline & $\begin{array}{c}\text { Pantoprazole } \\
\text { all }\end{array}$ & & $\begin{array}{c}\text { Pantoprazole } \\
0-4 \text { hrs }\end{array}$ & & $\begin{array}{c}\text { Pantoprazole } \\
>4 \mathrm{hrs}\end{array}$ & & $\begin{array}{c}\text { Pantoprazole } \\
>6 \mathrm{hrs}\end{array}$ & \\
\hline & $(n=46)$ & $(n=112)$ & $\begin{array}{c}P \\
\text { value }\end{array}$ & $(n=65)$ & $\begin{array}{c}P \\
\text { value }\end{array}$ & $(n=47)$ & $\begin{array}{c}P \\
\text { value }\end{array}$ & $(n=40)$ & $\begin{array}{c}P \\
\text { value }\end{array}$ \\
\hline & \multicolumn{2}{|c|}{ Number of pts. (\%) } & & $\begin{array}{l}\text { Number of } \\
\text { pts. }(\%)\end{array}$ & & $\begin{array}{l}\text { Number of } \\
\text { pts. }(\%)\end{array}$ & & $\begin{array}{l}\text { Number of } \\
\text { pts. }(\%)\end{array}$ & \\
\hline \multicolumn{10}{|l|}{$\begin{array}{l}\text { Endoscopic signs of bleeding } \\
\text { from duodenal ulcers }\end{array}$} \\
\hline Active bleeding & $9(19.5 \%)$ & $15(13.4 \%)$ & 0.32 & $13(20.0 \%)$ & 0.95 & $2(4.3 \%)$ & 0.02 & $2(5.0 \%)$ & 0.04 \\
\hline Nonbleeding visible vessel & $11(23.9 \%)$ & $22(19.6 \%)$ & 0.55 & $12(18.5 \%)$ & 0.48 & $10(21.3 \%)$ & 0.76 & $10(25.0 \%)$ & 0.91 \\
\hline Clot & $5(10.9 \%)$ & $28(25.0 \%)$ & 0.04 & $20(30.8 \%)$ & 0.01 & $8(17.0 \%)$ & 0.39 & $6(15.0 \%)$ & 0.57 \\
\hline Pigmented spot and clean base & $21(45.6 \%)$ & $47(41.9 \%)$ & 0.67 & $20(30.8 \%)$ & 0.11 & $27(57.4 \%)$ & 0.26 & $22(55.0 \%)$ & 0.39 \\
\hline Urgent endoscopy & $3(6.5 \%)$ & $8(7.1 \%)$ & 0.82 & $3(4.6 \%)$ & 0.54 & $5(10.6 \%)$ & 0.75 & $3(7.5 \%)$ & 0.65 \\
\hline Recurrent bleeding & $4(8.7 \%)$ & $18(16.1 \%)$ & 0.22 & $10(15.4 \%)$ & 0.29 & $8(17.0 \%)$ & 0.23 & $7(17.5 \%)$ & 0.22 \\
\hline Emergency surgery & $2(4.3 \%)$ & $6(5.3 \%)$ & 0.79 & $5(7.7 \%)$ & 0.48 & $1(2.1 \%)$ & 0.54 & $1(2.5 \%)$ & 0.64 \\
\hline Mortality & $1(2.2 \%)$ & $8(7.1 \%)$ & 0.22 & $3(4.6 \%)$ & 0.49 & $5(10.6 \%)$ & 0.09 & $4(10.0 \%)$ & 0.12 \\
\hline
\end{tabular}

$P$ values were calculated for comparison between saline infusion group and pantoprazole infusion group patients with different durations of pantoprazole administration.

been at different risks of ulcer bleeding. The effect of highdose pantoprazole on clot formation and stability in patients taking aspirin or NSAIDs is unknown.

Third, we only analyzed the data of those ulcer bleeding patients who were admitted on duty hours. However, one advantage of our study is that it reflects the real life situation using high-dose PPI inhibitors as a replacement of immediate urgent endoscopy during the night hours.

In conclusion, according to our retrospective analysis profound acid suppression in gastroduodenal ulcer bleeding patients awaiting endoscopy did not decrease significantly the ratio of active bleeding and the need for endoscopic therapy; however a trend of less active bleeding was seen with longer pantoprazole treatment. Preemptive administration of high-dose pantoprazole for longer than 4 hours decreased the severity of bleeding at first endoscopy in gastric ulcer patients but not in duodenal ulcer patients.

\section{References}

[1] A. N. Barkun, M. Bardou, E. J. Kuipers et al., "International consensus recommendations on the management of patients with nonvariceal upper gastrointestinal bleeding," Annals of Internal Medicine, vol. 152, no. 2, pp. 101-113, 2010.

[2] G. I. Leontiadis, V. K. Sharma, and C. W. Howden, "Proton pump inhibitor therapy for peptic ulcer bleeding: cochrane collaboration meta-analysis of randomized controlled trials," Mayo Clinic Proceedings, vol. 82, no. 3, pp. 286-296, 2007. 
[3] J. Y. W. Lau, J. Y. Sung, K. K. C. Lee et al., "Effect of intravenous omeprazole on recurrent bleeding after endoscopic treatment of bleeding peptic ulcers," New England Journal of Medicine, vol. 343, no. 5, pp. 310-316, 2000.

[4] M. Bardou, Y. Toubouti, D. Benhaberou-Brun, E. Rahme, and A. N. Barkun, "Meta-analysis: proton-pump inhibition in high-risk patients with acute peptic ulcer bleeding," Alimentary Pharmacology and Therapeutics, vol. 21, no. 6, pp. 677686, 2005.

[5] L. Laine and K. R. McQuaid, "Endoscopic therapy for bleeding ulcers: an evidence-based approach based on meta-analyses of randomized controlled trials," Clinical Gastroenterology and Hepatology, vol. 7, no. 1, pp. 33-47, 2009.

[6] L. Laine and D. M. Jensen, "Management of patients with ulcer bleeding," American Journal of Gastroenterology, vol. 107, no. 3, pp. 345-360, 2012.

[7] F. W. Green, M. M. Kaplan, L. E. Curtis, and P. H. Levine, "Effect of acid and pepsin on blood coagulation and platelet aggregation. A possible contributor to prolonged gastroduodenal mucosal hemorrhage," Gastroenterology, vol. 74, no. 1, pp. 38-43, 1978.

[8] A. Berstad, "Does profound acid inhibition improve haemostasis in peptic ulcer bleeding?" Scandinavian Journal of Gastroenterology, vol. 32, no. 4, pp. 396-398, 1997.

[9] S. E. Patchett, H. Enright, N. Afdhal, W. O'Connell, and D. P. O'Donoghue, "Clot lysis by gastric juice: an in vitro study," Gut, vol. 30, no. 12, pp. 1704-1707, 1989.

[10] J. Y. Lau, W. K. Leung, J. C. Y. Wu et al., "Omeprazole before endoscopy in patients with gastrointestinal bleeding," The New England Journal of Medicine, vol. 356, no. 16, pp. 1631-1640, 2007.

[11] A. Sreedharan, J. Martin, G. I. Leontiadis et al., "Proton pump inhibitor treatment initiated prior to endoscopic diagnosis in upper gastrointestinal bleeding.," Cochrane Database of Systematic Reviews, vol. 7, p. CD005415, 2010.

[12] A. N. Barkun, "Should every patient with suspected upper GI bleeding receive a proton pump inhibitor while awaiting endoscopy?" Gastrointestinal Endoscopy, vol. 67, no. 7, pp. 1064-1066, 2008.

[13] C. J. Van Rensburg, M. Hartmann, A. Thorpe et al., "Intragastric $\mathrm{pH}$ during continuous infusion with pantoprazole in patients with bleeding peptic ulcer," American Journal of Gastroenterology, vol. 98, no. 12, pp. 2635-2641, 2003.

[14] A. Avgerinos, S. Sgouros, N. Viazis et al., "Somatostatin inhibits gastric acid secretion more effectively than pantoprazole in patients with peptic ulcer bleeding: a prospective, randomized, placebo-controlled trial," Scandinavian Journal of Gastroenterology, vol. 40, no. 5, pp. 515-522, 2005. 


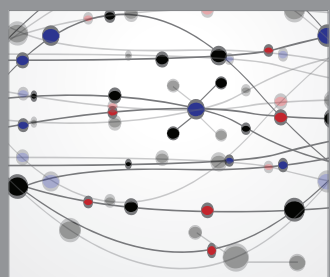

The Scientific World Journal
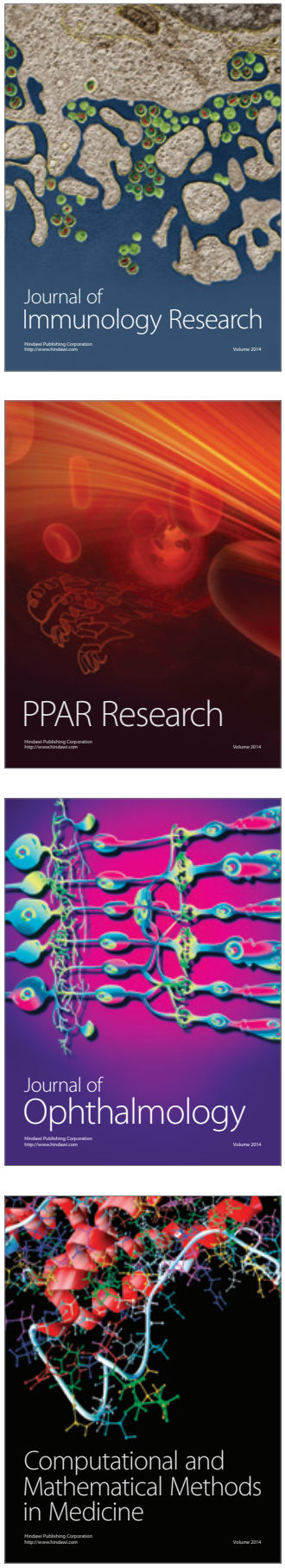

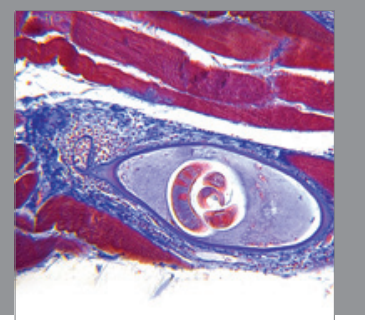

Gastroenterology

Research and Practice
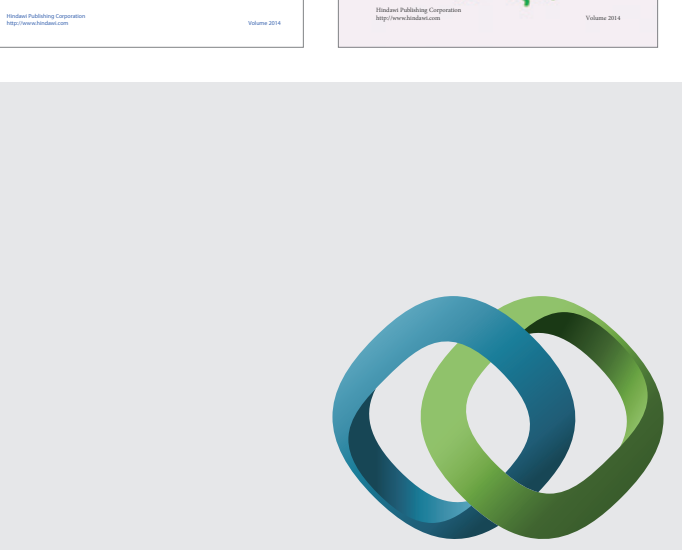

\section{Hindawi}

Submit your manuscripts at

http://www.hindawi.com
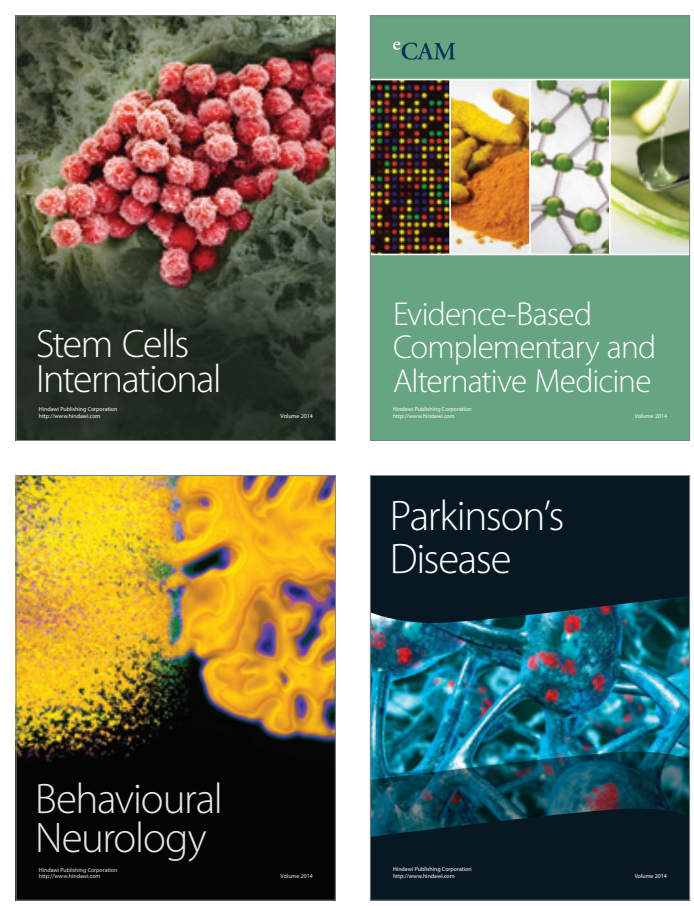

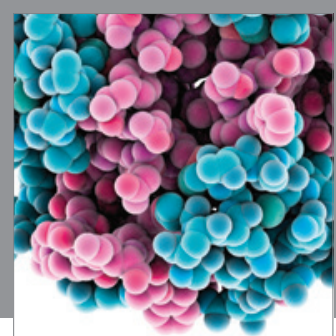

Journal of
Diabetes Research

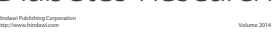

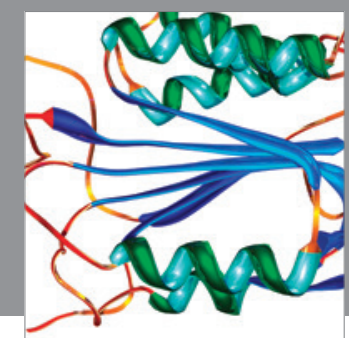

Disease Markers
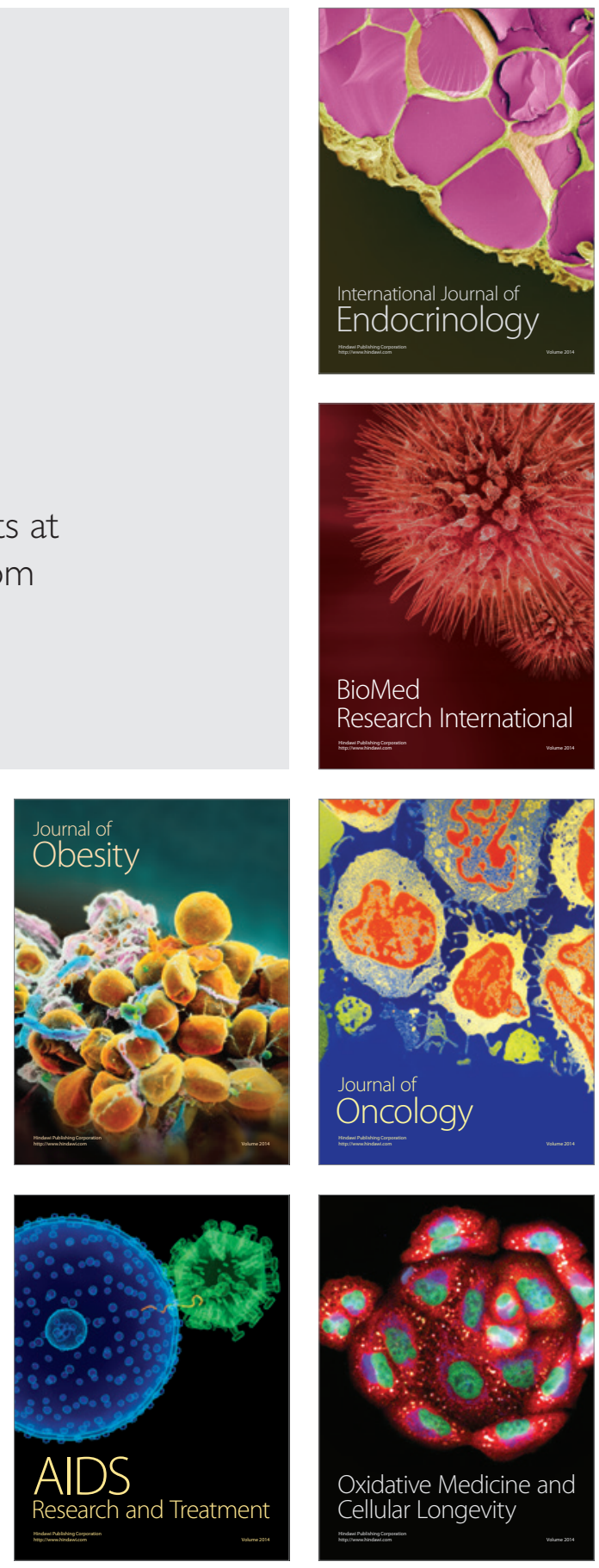